\title{
Maximum power point tracker of a photovoltaic system using sliding mode control
}

\author{
M. I. Arteaga Orozco, J. R. Vázquez, P. Salmerón, S. P. Litrán, F. J. Alcántara \\ Departamento de Ingeniería Eléctrica y Térmica \\ Escuela Politécnica Superior, Universidad de Huelva \\ Ctra. de Palos de la Frontera s/n, 21819, Palos de la Frontera, Huelva, Spain \\ Phone: +34-959217590, Fax: +34-959217304
}

e-mail: maria.arteaga@die.uhu.es, vazquez@uhu.es, salmeron@uhu.es, salvador@uhu.es, benju@uhu.es

\begin{abstract}
In this paper, a maximum power point tracker method using sliding mode control for a photovoltaic system is presented. The system includes a photovoltaic array, a DC/DC converter and a DC/AC inverter connected to a load. The designed control regulates the converter output voltage and it maximizes the power generated by the photovoltaic array. To obtain it, the sliding surface used to control the DC/DC converter is adjusted according to PV array output power. The control law designed and the results in a simulation platform will be presented.
\end{abstract}

\section{Key words}

Photovoltaic system boost converter, sliding mode control, maximum power point.

\section{Introduction}

Nowadays, photovoltaic (PV) systems are used as energy source in many cases. Most commonly applied PV systems can be found in remote and rural areas where no public grid is available. A typical small photovoltaic power system (off-grid) can contain the following components: solar PV array, with a number of series/parallel interconnected solar modules and protection elements, a DC/DC converter, a DC/AC inverter and a control system (Figure 1).

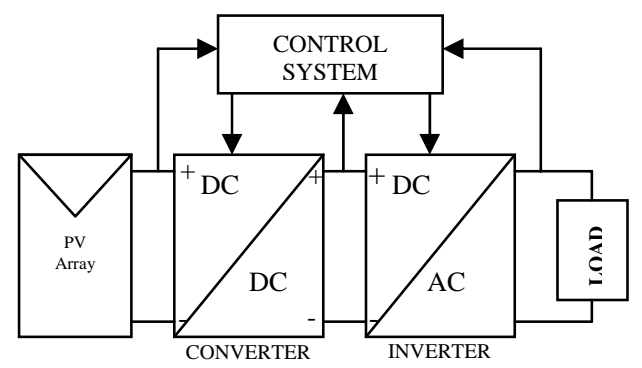

Fig. 1. Basic structure photovoltaic system
This target of control system is that the PV array will maximize the electrical power with a given irradiance. The control should guarantee that the dc power will be transformed with high efficiency to the load.

In order to archive the maximum power point (MPP) of the PV array, it is necessary maintain it at their optimum point operating. The MPP varies with the solar radiation and the temperature. The characteristic curves specify a unique operating point at which maximum possible power is delivered. At the MPP, the PV system operates at its highest efficiency.

Many methods have been developed to determine the MPP. For example, Ibrahimm and Houssing employed the look-up table on a microcomputer to track MPP, Midya et al. applied a dynamic MPP tracker to PV appliances, and Kuo and Liang proposed a single-stage MPP controller using the slope the power versus voltage, [1-3]. Dual boost converter based MPP tracking using fuzzy logic has been reported, [4]. Another approach is based on variable structure control and is applied to a buck converter, [5]. Too, there is an approach based on a perturbation and observation method, where the reference voltage varies periodically when the MPP is reached, [6].

In this work, a control that regulates the voltage of the DC/DC converter and maximizes the power generated by the photovoltaic array will be presented. The system consists of three closed loops, two inner loops and one outer loop. The DC/DC converter has a control loop which regulates the output voltage irrespective of the input voltage variations, and a sliding mode control that searches the maximum power point of the PV array. The proposed system has an independent control loop for the PWM inverter.

In this control system, it is necessary to measure the PV array output power and to change the duty cycle of the DC/DC converter control signal. So, the PV array output power is measured and compared to the previous PV array output power. Depending on the result of the 
comparison, the optimal reference current of sliding mode control is changed and the process is repeated until the maximum power is reached.

The rest of this paper is organized as follows. Section II introduces the basic principle of the PV system and a system description. Section III describes the proposed sliding controller. Simulation results and conclusions are finally discussed in the last section.

\section{System Description}

\section{A. Photovoltaic system}

A real PV array has been modeled. It consists of $30 \mathrm{PV}$ modules with $36 \times 2$ monocrystalline silicon solar cells each one, connected in series and parallel. Each module can produce $106 \mathrm{~W}$ of DC electrical power with an area of 126.5 square centimeters. The array is configured as follows: fifteen modules are connected in series, resulting a nominal operating voltage of $325 \mathrm{~V}$. Then, 2 of these series strings are connected in parallel, resulting in a current of 6A. The rated power of the PV array is $2.6 \mathrm{~kW}$ (DC).

In order to allow the interaction between a DC/DC converter and the PV array, a simulation model for a PV array has been developed, including the dependence of the PV array output with the irradiance and temperature. The model was implemented in Simulink, helped by the SimPowerSystem blockset (figure 2).

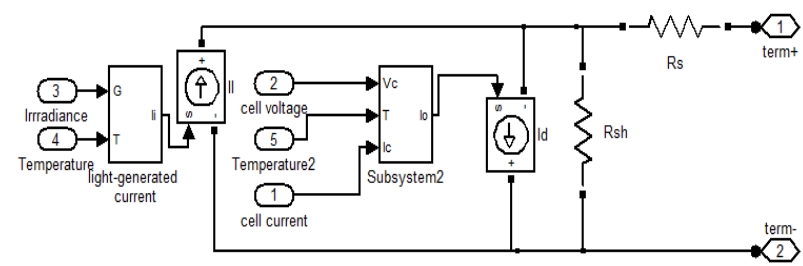

Fig. 2. Equivalent circuit of a PV cell

This equivalent circuit models the general form the equation that relates current and voltage [7] in a photovoltaic cell:

$$
I=I_{l}-I_{o}\left(e^{q \frac{\left(V+R_{s} I\right)}{\eta K T_{K}}}-1\right)-\frac{V+R_{s} I}{R_{s h}}
$$

where $I$ and $V$ are cell output current and voltage, $I_{o}$ is the cell reverse saturation current; $I_{l}$ is the light-generated current; $R_{s}$ and $R_{s h}$ are series and shunt resistance, $q$ is electronic charge, $\mathrm{K}$ is Boltzmann's constant, and $T_{K}$ is cell temperature in ${ }^{\circ} \mathrm{K}$.

Figs. 3(a) and 3(b) present the current-voltage and power-voltage output characteristics of a photovoltaic array for different solar isolation with temperature of $25^{\circ} \mathrm{C}$.

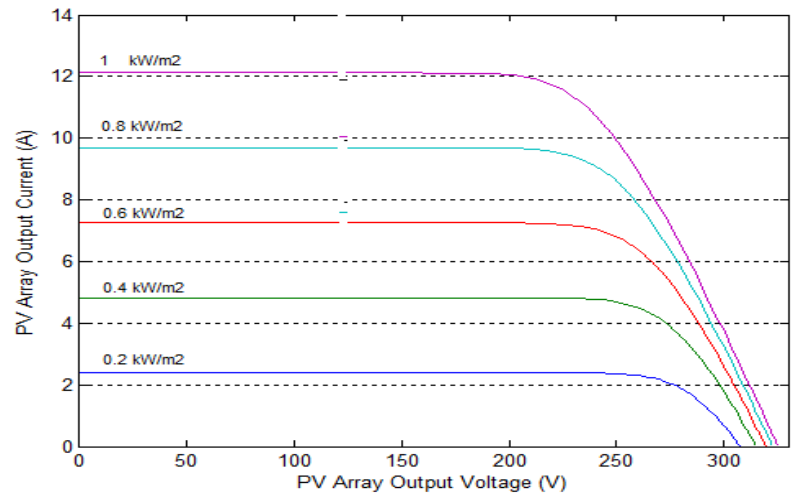

(a)

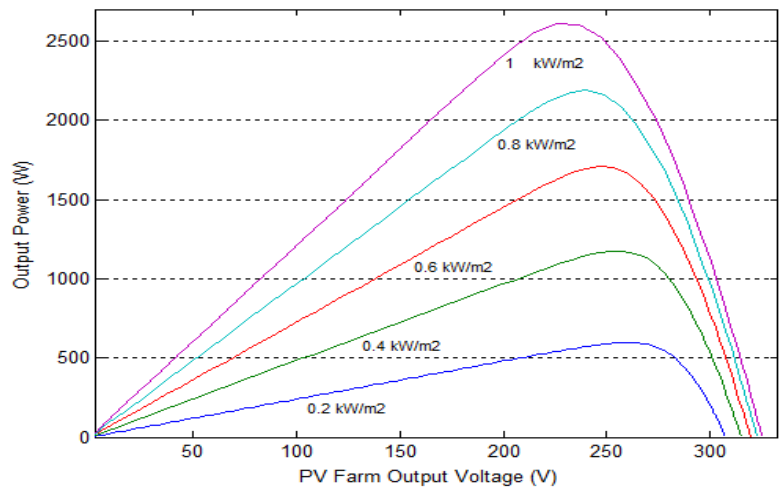

(b)

Fig. 3. Characteristic of a PV array with constant irradiation and temperature of $25^{\circ} \mathrm{C}$ : (a) current-voltage graph and (b) power-voltage graph.

In general, PV modules have nonlinear voltage-current characteristics, and there is only one unique operating point for a PV with a maximum output power under particular conditions.

\section{B. Boost converter}

In this section, the state-space model of the boost converter that will be used to evaluate the sliding mode control is presented.

A boost converter is simply is a particular type of power converter with an output DC. This type of circuit is used to 'step-up' a source voltage to a higher, regulated voltage, allowing one power supply to provide different driving voltages. The basic boost converter circuit consists of only a switch (typically a transistor), an inductor, and a capacitor. The specific connections are shown in figure 4.

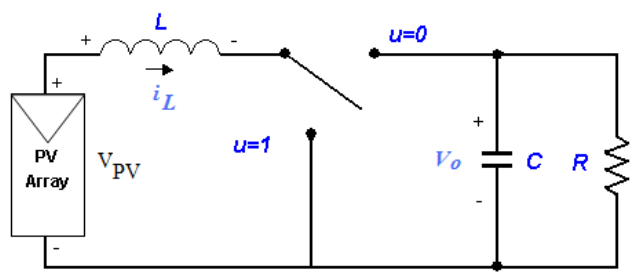

Fig. 4. Boost converter 
Applying Kirchhoff's rules around the loops, it can obtain the ideal mathematical model of this circuit:

$$
\begin{aligned}
& L \frac{d i_{L}}{d t}=V_{P V}-v_{o}(1-u) \\
& C \frac{d v_{o}}{d t}=i_{L}(1-u)-\frac{v_{o}}{R}
\end{aligned}
$$

where $i_{L}$ is the current across the inductor, $v_{o}$ is the voltage in the capacitor. Parameters $R, L$ and $C$ are supposed to be known constants. $u \in\{0,1\}$ defines the switch position and $V_{P V}$ is voltage supplied by photovoltaic array.

The gain from the boost converter is directly proportional to the duty cycle ( $D$ ), or the time the switch is 'on' each cycle.

$$
\frac{v_{o}}{V_{P V}}=\frac{1}{1-D}
$$

When boost converter is used in PV applications, the voltage input change continuously with atmospheric conditions. Therefore, the duty cycle should change to track the maximum power point of photovoltaic array.

This converter should support input voltages in a wide range from 100 to $325 \mathrm{~V}$. Under such conditions, the duty ratio $D$ is adjusted to regulate the output voltage at 400 $\mathrm{V}$. For the given range, $D$ is in a range of [0.76-0.20] and the output current is maximum when $D=0.33$.

The 400 Volts obtained at boost converter are applied to an IGBT two-level inverter to generate a sinusoidal output voltage of $50 \mathrm{~Hz}$. The IGBT inverter uses Pulse Width Modulation (PWM) at a $1050 \mathrm{~Hz}$ carrier frequency. The circuit is discretized at a sample time of $1 \mu \mathrm{s}$. The IGBT inverter is controlled with a PI regulator in order to maintain to $230 \mathrm{Vrms}, 50 \mathrm{~Hz}$ at the load terminals.

Considering this model as starting point, our aim is to find a control law that provides voltage regulation at the converter output, and guarantees the maximum power point of the PV array.

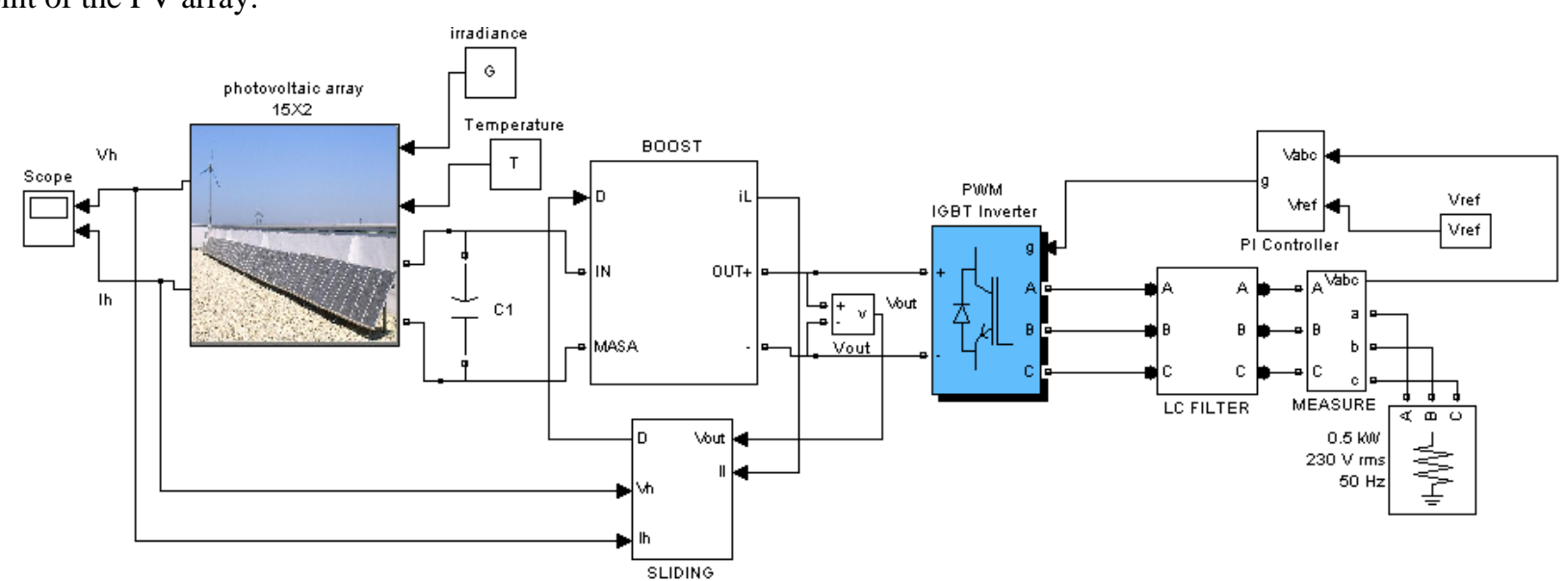

Fig. 5. Photovoltaic array interconnected to AC load

\section{Control design}

Sliding mode control is one of the effective nonlinear robust control approaches since it provides system dynamics with an invariance property to uncertainties once the system are controlled in the sliding mode [8].

Considering the model of DC/DC converter (2)-(3) the following sliding surface $S($.) is proposed:

$$
\begin{aligned}
& u=\left\{\begin{array}{lll}
1 & \text { if } \quad & S\left(v_{o}, u, \xi\right)>0 \\
0 & \text { if } & S\left(v_{o}, u, \xi\right)<0
\end{array}\right. \\
& S\left(v_{o}, u, \xi\right)=i_{L}-i_{L R E F}+K_{0} \xi \\
& \dot{\xi}=v_{o}-V_{e}, \xi(0)=0
\end{aligned}
$$

where $K_{0}$ is a positive constant and $i_{\text {LREF }}$ is reference value of inductor current and $V_{e}$ is desired output voltage $(400 \mathrm{~V})$.

The sliding surface assures that the sliding motion is reached and regulates output voltage boost converter. By measuring the array voltage and current, the array power is calculated and compared to the previous array output power. Depending this comparison $i_{L R E F}$ is recalculated:

$$
i_{\text {LREF }}[n+1]=i_{\text {LREF }}[n]+\Delta i_{\text {LREF }}
$$

where $i_{L R E F}[n]$ and $\Delta i_{\text {LREF }}$ are reference current and its perturbation, respectively. Defining to

$$
\begin{gathered}
\Delta i_{\text {LREF }}=\alpha \frac{\Delta P_{P V}}{\Delta V_{P V}} \\
\Delta P_{P V}=P[n]-P[n-1] \\
\Delta V_{P V}=V_{P V}[n]-V_{P V}[n-1]
\end{gathered}
$$

where $V_{P V}[n], I_{P V}[n]$ and $P_{P V}[n]$ represent the voltage, current and power of PV array, respectively, in which $[n]$ denotes the iteration number; and $\alpha$ is a positive constant. 


\section{Simulations results}

A Simulink-Matlab simulation of closed-loop PV (figure 5) has been carried out when the load is $0.5 \mathrm{~kW}$.

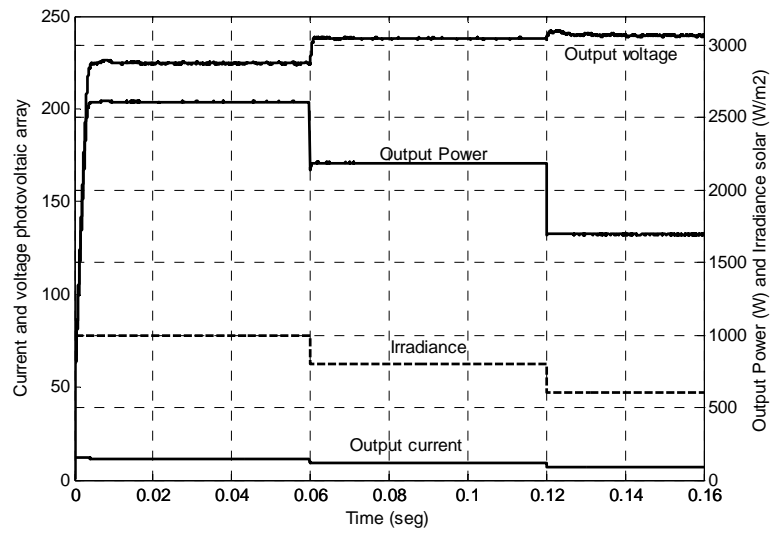

Fig. 6. Evolution of $V_{P V}, I_{P V}$ and $P_{P V}$ to difference irradiances solar

Figure 6 shows the evolution of the current, voltage and power PV array for $1000 \mathrm{~W} / \mathrm{m}^{2}$ and for successive irradiance steps applied at $\mathrm{t}=0.6 \mathrm{seg}\left(800 \mathrm{~W} / \mathrm{m}^{2}\right)$ and $\mathrm{t}=1.2$ seg $\left(600 \mathrm{~W} / \mathrm{m}^{2}\right)$. It can be seen than the system reaches the maximum power point in each step as it can be verified from figure 3 .

Figure 7 shows the load voltage for the irradiance step and figure 8 shows the evolution of the modulation index. The time response is nearly $10 \mathrm{~ms}$ for a final output of 230 Vrms.

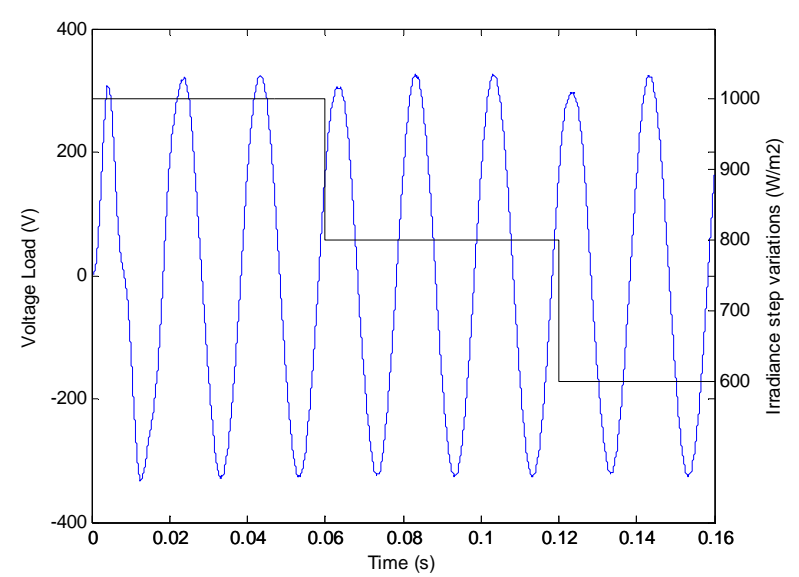

Fig. 7. Evolution of load voltage to difference irradiances solar

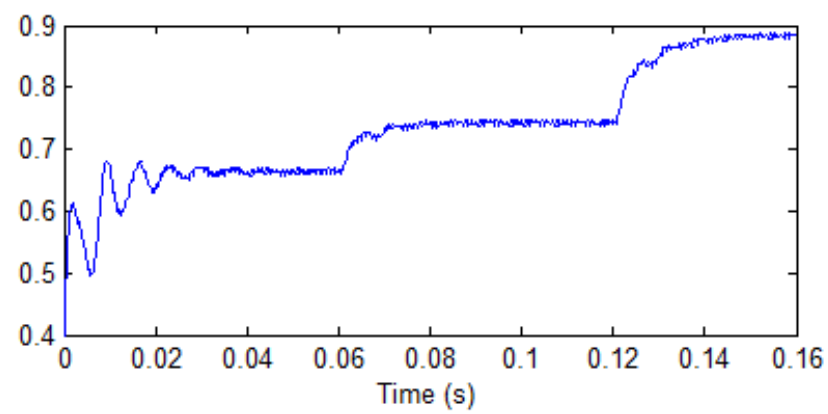

Fig. 8. Evolution of index modulation

\section{Conclusions}

In this paper, a sliding mode integral control of the boost converter has been analyzed. The reported controller uses the output power of the PV array, output voltage of the converter and an input signal, which in this case is the switching signal. The control law provides voltage regulation at the converter output, and guarantees the maximum power point of the PV array.

A practical case developed in a Matlab/Simulink simulation platform has been presented, and the results confirm the adequate performance of designed control. So, the dynamical response of the control is around one period of the voltage supply.

Besides, the control law can be easily implemented by means of standard operational amplifiers, analog multipliers and digital devices in an experimental platform.

\section{References}

[1] Ibrahim, H. E.-S. A. and Houssiny, F. F., "Microcomputer Controlled Buck Regulator for Maximum Power Point Tracker for DC Pumping System Operates from Photovoltaic System," Proceedings of the IEEE International Fuzzy Systems Conference, August 22-25, Vol. 1, pp. 406-411 (1999).

[2] Midya, P., Kerin, P. T., Turnbull, R. J., Reppa, R. And Kimball, J., "Dynamic Maximum Power Point Tracker for Photovoltaic Applications," Proceedings of the IEEE Power Electronics Specialists Conference, PESC, Vol. 2, pp. 1710-1716 (1996).

[3] Kuo, Y. C., Liang, T. J. and Chen, F. C., "Novel Maximum-Power-Point-Tracking Controller for Photovoltaic Energy Conversion System", IEEE Transactions on Industrial Electronics, Vol. 48, pp. 594601 (2001).

[4] Veerachary, M., Senjyu, T., and Uezato, K. "Feedforward maximum power point tracking of PV systems using fuzzy controller”. IEEE Transactions on Aerospace and Electronic Systems, Vol. 38, 3 (July 2002), 969-981.

[5] Miao, Z., W. Jie, et al., "The application of slide technology in PV maximum power point tracking system”, Fifth World Congress on Intelligent Control and Automation, WCICA, 2004.

[6] Koutroulis, E. And Voulgaris N. C., "Development of a Microcontroller-based photovoltaic Maximum power point tracking control system”, IEEE Transactions on Power Electronic, Vol. 16, No. 1, January 2001.

[7] Gow, J. A. and C. D. Manning, “ Development of a model for photovoltaic arrays suitable for use in simulation studies of solar energy conversion systems", Sixth International Conference on Power Electronics and Variable Speed Drives, 1996.

[8] V. Utkin, J. Guldner, and J. Shi, "Sliding Modes in Electromechanical Systems”, London, U.K.: Taylor \& Francis, 1999.

[9] R.D. Middlebrook and Slobodan Cuk, "A General Unified Approach to Modelling Switching-Converter Power Stages”, IEEE PESC’76 Rec., pp. 18-34, Cleveland, OH, June 8-10. 